\title{
O TREINAMENTO DE PLANEJADORES DO SETOR SAÚDE (1)
}

\author{
Reinaldo RAMOS
}

\begin{abstract}
Após destacar a importância dos recursos humanos na execução dos programas de saúde e destacar a atencâo que o problema tem merecido da Organizaçäo Mundial da Saúde, salienta-se que nos últimos anos essa atenç̃o vem sendo igualmente dispensada no preparo de pessoal de cúpula, destinado ao exercicio de atividades de planejamento. Fm seguida, é feita uma apreciagáo sumária sôbre os cursos de planejamento do setor saúder no tocante a seus objetivos e conteúdo, acompanhada de uma análise comparativa dos cursos realizados nos Estados Unidos da América, Trinidad e Tobago, Chile e Brasil. Finalmente, é pôsto em evidência o relevante papel desempenhado pela Organização Mundial da Saúde - através de seu organismo regional na implantaçăo c consolidação dêsses cursos em países das Américas.
\end{abstract}

\section{I - I N T R O D U C $\mathrm{AO}$}

Gostaria inicialmente de manifestar, em meu nome pessoal e também em nome da Cadeira de Administração Sanitária desta Escola, minha satisfação por êste encontro com os ilustres colegas representantes de países asiáticos, ocupando cargos de direção nos respectivos serviços nacionais de saúde.

Este acontecimento é tanto mais significativo, se considerarmos que tem o patrocínio da Organização Mundial da Saúde, entidade indissolùvelmente ligada a esta Casa, pôsto que o fundador e primeiro diretor da Faculdade de Higiene e Saúde Pública de São Paulo — o Professor Geraldo Horacio de Paula Souza foi um líder da saúde pública internacional e um dos idealizadores e propugna. dores da criação de um organismo mundial que ocupasse o lugar da antiga Sociedade de Higiene da Liga das Na- ções. E também significativa a coincidência de que os senhores estejam chegando a São Paulo na ocasião em que a Faculdade acaba de reverenciar a memó. ria de Paula Souza pelo transcurso do $17^{\circ}$ aniversário de seu falecimento, ocorrido a 2 de maio de 1951.

Estivesse êle vivo, e sem dúvida teria orgulho da pujança, do prestígio e do volume de realizaçōes da organização que ajudou a criar e que representou o objeto central de suas preocupações nos últimos anos de sua existência. Realizaçōes que vão desde $o$ contrôle da filariose numa remota ilha do Pacífico, até a proteção sanitária dos peregrinos que anualmente visitam Meca; que vão desde a promoção de pesquisas para o preparo de novas vacinas, até a organização de serviços médicos de emergência para socorrer a população do Congo Belga; que vão desde

Recebido para publícaçáo em 23-7-1968.

(1) Da Cadeira de Administração Sanitária da Faculdade de Higiene e Saúde Pública da USP. Aula proferida no Curso Itinerante de Orientação em Planejamento de Saúde para Diretores de Serviços Nacionais de Saúde do Sudeste Asítíco, São Paulo, Malo de 1968. 
RAMOS, R. - o treinamento de planejadores do setor saúde. Rev. Saúde públ., S. Paulo, 2(2) :207-215, dez. 1968

a assessoria direta aos serviços de saúde dos países membros, até as medidas de longo alcance, visando a reforçar a estrutura dêsses serviços através de programas de preparo de pessoal para seus diferentes níveis funcionais.

Os problemas ligados à formação de pessoal têm merecido especial atenção da Organização Mundial da Saúde. E tal preocupação é plenamente justificada, se atentarmos para o fato de que, sendo o setor saúde um setor fundamentalmente produtor de serviços, os recursos humanos representam parcela considerável oscilando entre 60 e $85 \%$ - dos custos unitários de operação dos instrumentos produtores dêsses serviços.

Nesta década de 60 , os programas de formação de pessoal para exercer atividades no campo da saúde ganharam nova dimensão, porque já não se trata apenas de aumentar a quantidade ou de melhorar a qualidade dos recursos humanos empenhados na prestação direta de serviços, mas de preparar pessoal de cúpula para a tarefa não menos importante de racionalizar o processo decisório.

A problemática da saúde tende cada vez mais a ser concebida como o resultado de um confronto entre necessidades e recursos.

As necessidades decorrentes da perda da saúde são múltiplas, variáveis e impossiveis de satisfação total.

Os recursos com que se conta são escassos, mal distribuídos, mal utilizados, de uso competitivo e com diferente produtividade.

Face a esta problemática, teriamos teòricamente três alternativas:

1. Limitação ou redução das necessidades.

2. Aumento dos recursos até o limite de satisfação das necessidades.

3. Uso racional dos instrumentos disponíveis.
Um incremento racional e o uso racionalizado dos recursos são as alternativas que podemos considerar na prática.

$O$ incremento racional dos recursos, resultando de um fenômeno competitivo com outros setores, tem um limite. Não é possível, portanto, nivelar recursos com necessidades. E se não é possível nivelar recursos com necessidades, então é evidente que não podemos satisfazer a tôdas as necessidades de saúde. $O$ que obriga, conseqüentemente, a concentrar os escassos recursos racionalizados no atendimento das necessidades de maior prioridade.

Se trazemos para o campo da saúde a problemática da economia - o que nos põe perante o dilema de alocar recursos escassos para fins alternativos - é imperioso que o nível superior da organização disponha dos elementos indispensáveis para adotar as melhores decisões. E o instrumento com que contamos para isso é o planejamento.

Concebemos o planejamento, em seu sentido mais amplo, como o meio de alcançar o desenvolvimento integral de uma comunidade nacional - ou seja, o planejamento econômico e social - e o definimos como a "política científica ou o govêrno racional de um conjunto social para conduzí-lo às mais elevadas formas de vida coletiva, dando, nesta última, oportunidades para que todos os indivíduos se superem, de acôrdo com suas capacidades".

Especìficamente no campo da saúde, o planejamento tem como objetivos básicos:

1. A tomada de decisões racionais para determinar quais são as necessidades prioritárias e em que grau devem ser satisfeitas. Além da simples magnitude das necessidades, as prioridades devem ser determinadas em função de propósitos sociais e de maior vulnerabilidade.

2. A tomada de decisões racionais para determinar o uso mais adequado dos recursos. A racionalidade no uso dos recursos é fundamentalmente um problema de eficiência. 
RAMOS, R. - O treinamento de planejadores do setor saúde. Rev. Saúde públ., S. Paulo, 2(2) :207-215, dez. 1968.

O planejamento é um meio instrumental para conseguir o desenvolvimento, e para desenvolver-se é necessário alcançar melhores níveis de vida. Tais níveis foram atingidos pelos países desenvolvidos através de um processo normal e aparentemente espontâneo. Em troca, os países subdesenvolvidos devem surgir quase diretamente da pobreza, sem esperar êsse processo aparentemente espontâneo, que alguns especialistas crêem impossível de produzir-se "naturalmente", dadas as próprias características do subdesenvolvimento.

$E$ eis aqui um traço de união entre nós. Apesar das diferenças existentes entre nossos países - diferenças de natureza histórica, de natureza cultural, de natureza lingüística, de natureza social, etc. - estamos todos colocados sob um mesmo e vasto denominador comum, que é o subdesenvolvimento. Nossos problemas poderão variar no tocante às manifestações de efeito; seus fatôres causais, porém, são essencialmente os mesmos.

Face à complexidade dos problemas do subdesenvolvimento e da urgência em encontrar soluções, o planejamento está se impondo em todos os países como algo indispensável e não simplesmente necessário. Perroux (1), assinala que "se nos países adiantados o planejamento parece cada vez mais conveniente para determinar as consequiências longinquas que serão produzidas pela presente açâo dos agentes econômicos, e orientar a economia para uma estrutura nova e mais vantajosa, com maior razão o planejamento se impõe nos países em desenvolvimento, onde se necessita de um trabalho consciente e perseverante para promover o progresso da economia e o melhoramento social".

Um último aspecto a mencionar, nestas considerações preliminares, diz respeito ao caráter integral que o planejamento deve assumir. E isto decorre do fato de que "tanto o planejamento como o bem-estar
- fim último do desenvolvimento - são realidades complexas, integradas por diversos fatôres heterogêneos e componentes, complementares e interdependentes, correspondentes às diferentes funções $e$ campos de ação de uma sociedade". Esta a razão porque o planejamento no campo da saúde e, em decorrência, os planos nacionais de saúde, devem ser obrigatòriamente partes integrantes do processo de planejamento do desenvolvimento. Não se recomenda o planejamento isolado, pôsto que as ações isoladas e descoordenadas, apesar de sua racionalidade dentro de um setor, significam, em última instância, esforços dispersos, recursos mal aproveitados e resultados gerais ineficientes.

Até mesmo quando não existe um plano global, o plano setorial exige a colocação de uma hipótese de desenvolvimento, de sorte a poder-se implantar de maneira adequada. 0 mesmo se pode dizer se dentro de um setor não há condições de fazer planejamento. A superação dêsse obstáculo exige, como no caso anterior, a formulação de uma política básica, de tipo setorial, que se possa adotar como marco de referência para servir a programações isoladas.

E esta a linha de pensamento e ação que a passos lentos vai ganhando terreno na maioria dos países latino-americanos, enfrentando as dificuldades inerentes a todo processo de mudança. E um de seus resultados mais positivos consiste sem dúvida na implantação de cursos para a formação de especialistas em planejamento do setor saúde, objeto específico desta palestra.

\section{Ir - OS CURSOS DE PLANEJAMENTO}

\section{Objetivos}

Os cursos de planejamento do setor saúde têm sido promovidos visando aos seguintes objetivos gerais:

(1) PERROUX apud TEJADA de RIVERO, D. A. op. cit. 
RAMOS, R. - O treinamento de planejadores do setor saúde. Rev. Saúde públ., S. Paulo, 2(2) :207-215, dez. 1968.

a) Ministrar ensino intensivo sôbre os princípios e métodos do planejamento da saúde.

b) Familiarizar os participantes com os conceitos, métodos e conteúdo da pro. gramação econômica e social.

c) Propiciar o intercâmbio de conhecimentos e experiências.

Especificamente, êsses cursos se destinam ao preparo de profissionais para exercer funções de planejamento do setor saúde, ou que, desempenhando funções docentes em institutos universitários, possam de alguma forma contribuir para a divulgação e implantação do processo.

Levando em conta os objetivos dos cursos de planejamento do setor saúde, ou seja, o fato de que êles não têm ou não devem ter finalidade meramente acadêmica ou especulativa, fica evidente que a seleção dos candidatos deve obedecer a um recrutamento de tipo preferencial.

Os cursos internacionais promovidos no Chile, por exemplo, se destinam a funcionários de alto nível dos serviços de saúde da América Latina, com formação e experiência em saúde pública, e estreitamente vinculados às atividades de formulação e execução de planos nacionais de saúde. É provável que essa referência um tanto ambiciosa a "planos nacionais de saúde" se deva ao fato de que o Chile é um país com govêrno de tipo unitário, onde, portanto, o planejamento de saúde pode mais fàcilmente ser concebido e implantado em têrmos nacionais.

Nos cursos realizados no Brasil, vem-se igualmente insistindo na necessidade de que os candidatos possuam formação básica em saúde pública, exigindo-se-lhes, ademais, uma experiência mínima de dois anos em função técnica, administrativa ou docente no campo da saúde. É claro que nem sempre todos êsses requisitos podem ser preenchidos pelo candidato; eventualmente, por uma questão política, isto é, quando encaminhados por uma instituição, têm sido aceitos candidatos não portadores de diploma de pós-graduação em saúde pública.

Por outro lado, em razão de ser o nosso um país de tipo federativo, não podemos pensar em planejamento apenas em têrmos nacionais, a cargo das instituições do setor saúde atuando na esfera federal. Há que considerar também o planejamento nas esferas estadual e territorial, abrangendo o espaço geográfico de cada um dos vinte e dois estados e três territórios federais em que está dividido o país. E mais ainda: considerando a existência de problemas comuns a vários estados problemas êsses por vêzes de caráter agudo, a reclamarem tratamento prioritário - o govêrno federal vem adotando a política de criação de organismos macro-regionais, destinados a promover o desenvolvimento sócio-econômico dessas áreas, aí incluídos, naturalmente, os aspectos relacionados ao setor saúde. Um dêsses organismos macro-regionais, por exemplo, é a SUDENE - Superintendência de Desenvolvimento do Nordeste, que os senhores terão oportunidade de visitar durante sua permanência no Brasil; outro, a SU. DAM - Superintendência de Desenvolvimento da Amazônia, com atuação nos estados e territórios federais que integram o Vale Amazônico; um terceiro, a SU. DESUL - Superintendência de Desenvolvimento do Sul - com jurisdição nos estados do extremo Sul do país.

Face a essa multiplicidade de esferas - federal, estadual e macro-regional e sem mencionar o nível local, é compreensível que os cursos brasileiros de planejamento do setor saúde não poderão cogitar apenas do preparo de pessoal para a formulação de planos nacionais de saúde, mas, genèricamente, para o exercício de funções de planejamento da saúde em quaisquer esferas e em quaisquer níveis.

\section{Conteúdo}

Existem acentuadas diferenças em relação ao conteúdo dos cursos de planejamento do setor saúde, promovidos ou em 
RAMOS, R. - O treinamento de planejadores do setor saúde. Rev. Saúde públ., S. Paulo, 2(2) :207-215, dez. 1968.

andamento em vários países das Américas. As informações disponíveis sôbre alguns dêsses cursos permitem identificar diferenças tanto no que diz respeito à parte introdutória, como também no tocante às técnicas de planejamento ministradas. Consideremos, a êsse propósito, o conteúdo dos cursos de planejamento realizados em quatro países, a saber: Estados Unidos da América, Trinidad e Tobago, Chile e Brasil.

\section{a) Estados Unidos da AmÉrica}

Os cursos norte-americanos têm a duração de 8 semanas e são promovidos pela Johns Hopkins University, com a colaboração da Organização Panamericana da Saúde. Merece destaque o fato de que o curso se inicia diretamente com a abordagem do tópico "Planejamento", em seus aspectos históricos, conceituais e instrumentais, após o que, pela altura da quinta semana, é apresentada uma única técnica de planejamento - a metodologia da programação local. Sòmente na sexta semana são ministradas noções de análise econômica, e o restante do período letivo é dedicado a questões de natureza prática, ligadas à elaboração e implantação de planos locais, regionais e nacionais de saúde, a programas de erradicação, etc.

Tem-se a impressão de que o enfoque do planejamento como um meio de alcançar o desenvolvimento integral de uma comunidade nacional, não é tomado em consideração. Se o é, isso não transparece no programa do curso.

\section{b) Trinidad e Tobago}

Os cursos de Trinidad e Tobago têm a duração de 6 semanas e resultam do esfôrço conjugado da Universidade das Indias Ocidentais, Ministério da Saúde e Organização Panamericana da Saúde.

Notamos já aqui a preocupação - em. bora um tanto tímida - em situar o processo de planejamento da saúde dentro de um quadro de referência, se bem que limitado àquele país. Assim é que são apresentadas e discutidas, durante um programa introdutório de uma semana, as condiçôes sociais e econômicas de Trinidad e Tobago; o histórico dos serviços de saúde do país e sua organização administrativa, bem como a organização dos sistemas de informação estatística e contábil; perspectivas presentes e futuras dos serviços de saúde.

A parte específica do programa compreende, igualmente, a ministração de uma única técnica de planejamento - a técnica de programação local - à qual são pràticamente destinadas as restantes 5 semanas do curso, com treinamento de campo numa área programática local.

\section{c) Chile}

Já os cursos internacionais de planejamento ministrados no Chile diferem substancialmente dos anteriores. Tais cursos têm a duração de 14 semanas, vêm sendo realizados a partír de 1962 e devem sua existência a um convênio celebrado entre o Instituto Latino-Americano de Planejamento Econômico e Social e a Organização Panamericana da Saúde. O espírito dêsse acôrdo emana dos convênios subscritos pelos países latino-americanos para planejar o seu desenvolvimento na corrente década.

O Instituto tem a seu cargo a apresentação das matérias atinentes ao desenvolvimento econômico e social e ao planejamento do desenvolvimento, para o que conta com uma brilhante equipe de economistas e sociólogos.

A Organização Panamericana da Saú de tem sob sua responsabilidade a apresentação dos tópicos saúde e desenvolvimento, e planejamento de saúde.

O curso conta, além disso, com a participação de outras entidades, a saber:

- O Serviço Nacional de Saúde, em aspectos ligados ao planejamento de saúde;

- A Comissão Econômica para a América (CEPAL), em matérias de desenvolvimento econômico e social; 
RAMOS, R. - O treinamento de planejadores do setor saúde. Rev. Saúde puibl., S. Paulo, I (2) :207-215, dez. 1968.

- E o Centro Latino-Americano de Demografia (CELADE), na abordagem do problema populacional.

A simples menção das organizações envolvidas nos cursos chilenos dá bem idéia da amplitude do quadro de referência dentro do qual é inserido o planejamento do setor saúde, revelando o reconhecimento de que a saúde não sòmente é um bem em si, mas também um fator indispensável do desenvolvimento.

Daí a preocupação em focalizar temas como as relaçóes entre a saúde e o desenvolvimento; a evolução econômica e social da América Latina; a evolução demográfica mundial, com ênfase na situação latino-americana; o planejamento do desenvolvimento econômico; sociologia do desenvolvimento; habitação e desenvolvimento; o problema agrário; o problema industrial; o problema educacional; a importância do setor público no processo do desenvolvimento.

E desnecessário frisar a importância da abordagem dêsses temas num curso de planejamento do setor saúde. Bastaria lembrar mais uma vez, primeiro, que o planejamento - inclusive da saúde - é um meio para alcançar o desenvolvimento, e que portanto as relações entre saúde e desenvolvimento devem ser identificadas com a possível precisão; e, em segundo lugar, salientar que já não mais satisfaz a apresentação do famoso círculo vicioso da doença e da pobreza em têrmos puramente líricos, mas em têrmos práticos, no sentido de determinar onde e como êsse círculo vicioso pode ser rompido.

Há um ponto, entretanto, em que o curso do Chile nos parece insuficiente $e$ incompleto: é que, tal como nos cursos dos Estados Unidos da América e de Trinidad e Tobago, apenas a técnica de programação local vem sendo ministrada, falha esta que sòmente agora se cogita de corrigir.

Tratando-se de técnica micro-dimensional, que limita o objeto do planejamento a uma área programática local, êsse instrumento metodológico não pode, por si só, conduzir à formulação de um plano nacional. Certos problemas de saúde ultrapassam o espaço geográfico da área programática e terão portanto que ser equacionados em nivel central; por outro lado, muitas deficiências e dificuldades de natureza administrativa, verificadas em nível local, são apenas reflexos de problemas cujas raízes estão situadas nos escalões superiores da organização, e que só poderão ser identificados e solucionados mediante a utilização das chamadas técnicas de programação do setor público.

Ocorre ainda que a demanda de serviços de saúde é um fenômeno dinâmico por natureza, condicionado por vários fatôres, entre os quais o incremento populacional; por sua vez, a oferta de serviços terá de assumir caráter também dinâmico, a fim de poder fazer face à demanda crescente, agravada pela depreciação e obsolescência do equipamento. Essa necessidade de aumentar a oferta para atender a uma demanda crescente nos leva ao emprêgo de outra técnica de planejamento - a técnica de elaboração $e$ avaliação de projetos de investimentos - cuja finalidade básica é promover o aumento da capacidade instalada, e cuja expressão temporal são os planos a médio prazo.

Técnicas de programação local, de programação do setor público e de elaboração e avaliação de projetos de investimentos necessitam de uma expressão operacional a curto prazo, e essa expressão operacional a curto prazo é representada pelo orçamento-programa; o que nos coloca ante a necessidade de ensino e utilização de mais uma técnica de planejamento: a técnica de programação orçamentária.

O planejamento de saúde - já ficou dito anteriormente - não pode constituir um processo isolado. Impôe-se a sua vinculação ao planejamento global, e surgem então as técnicas de articulação inter-setorial - análise de insumos criticos $e$ 
RAMOS, R. - O treinamento de planejadores do setor saúde. Rev. Saúde públ., S. Paulo, 2(2) :207-215, dez. 1968.

estudo do valor ágregado do setor - que têm por objetivo compatibilizar as metas do setor saúde com as dos demais setores, de sorte a constituirem um todo harmônico e coerente.

Informações mais detalhadas sôbre essas diferentes técnicas os senhores as terão quando de seu contato com os colegas da Escola Nacional de Saúde Pública. Nós só as mencionamos aqui para justificar a necessidade de sua ministraçāo nos cursos de planejamento do setor saú de, e ainda por ser esta uma das caracrísticas marcantes da orientação que vimos seguindo no Brasil.

\section{d) Brasil}

Os cursos brasileiros de planejamento do setor saúde vêm sendo realizados desde 1965, ano em que a SUDENE promoveu o primeiro dêles em colaboração com a Organização Panamericana da Saúde.

No presente, três instituições do país - contando, sempre, com a assistência da Organização Panamericana da Saúde - promovem regularmente cursos de planejamento:

- A SUDENE, que já ministrou três e está com o quarto em andamento;

- A Escola Nacional de Saúde Pública, do Ministério da Saúde, que em 1967 ofereceu o primeiro curso e deverá em junho próximo iniciar o segundo;

- E a Faculdade de Higiene e Saúde Pública da Universidade de São Paulo, que tem no momento o seu primeiro curso em andamento. $O$ curso de São Paulo vem contando, além da mencionada participação da Organização Panamericana da Saúde, com a colaboração da Escola Nacional de Saúde Pública e da Fundação Serviço Especial de Saúde Pública.

Os cursos realizados entre nós têm a duração de 16 semanas e seu conteúdo difere substancialmente do dos cursos anteriormente focalizados.
As primeiras cinco semanas do curso são dedicadas a um programa introdutório, compreendendo a apresentação e discussão de temas de administração geral e pública, economia, estatística e ciências sociais.

Este programa introdutório tem por finalidades atualizar conhecimentos, uniformizar conceitos e suprir eventuais deficiências na formação básica dos candidatos. Acreditamos que na medida em que as escolas de saúde pública ajustarem melhor seus currículos às necessidades do planejamento, tal programa poderá ser grandemente reduzido ou, o que nos parece mais vantajoso, substituído por outras disciplinas.

A segunda parte do curso, à qual em São Paulo foram destinadas 18 horas, compreende a conceituação de desenvolvimento e subdesenvolvimento econômicos; a conceituação de modêlo e a apresentação de modelos de desenvolvimento global; a apresentação dos esquemas conceitual e operacional do planejamento do setor saúde. Esta segunda parte, sobretudo, nos tópicos referentes à caracterização do subdesenvolvimento e à estratégia do planejamento para o desenvolvimento, é que em nosso entender deveria merecer uma abordagem mais detalhada, tal como se faz no Chile. Isso, porém, só se nos afigura factível quando o programa introdutório puder ser reduzido, já que não é aconselhável prolongar a duração total do curso.

Mas é na terceira parte, que se estende por nove semanas, que os cursos brasileiros levam a melhor, relativamente a seus congêneres dos outros países, face à variedade de instrumentos metodológicos proporcionada aos candidatos. Tôdas as técnicas de planejamento atrás referidas são apresentadas com o grau de detalhe que as condiçōes comportam, incluindo-se, no caso de algumas delas, a execuçáo de trabalhos práticos com a manipulação de modelos docentes. 0 treinamento de campo do curso que ora se desenvolve em São Paulo está sendo organizado de sorte 
RAMos, R. - O treinamento de planejadores do setor saúde. Rev. Saúde públ., S. Paulo, 2(2) :207-215, dez. 1968.

a permitir aos alunos o adestramento em três das técnicas ministradas: a de programação local, a de programação orçamentária e a de programação do setor público. As duas primeiras serão aplicadas numa área programática local já selecionada, distante cêrca de duas horas de São Paulo, onde os participantes trabalharão três unidades de saúde: um hospital de caridade, um centro de saúde e um pôsto de assistência materno-infantil. 0 treinamento da técnica de programação do setor público terá lugar numa das instituições da Secretaria de Saúde do Estado.

A última semana do curso é reservada para a realização, a cargo dos alunos, de seminários sôbre a estratégia para a implantação do processo de planejamento. No curso de São Paulo, êsses seminários estarão subordinados aos seguintes temas:

- A infra-estrutura administrativa e o planejamento do setor saúde.

- A infra-estrutura estatística e o planejamento do setor saúde.

- Aspectos sociológicos a considerar no processo de planejamento do setor saúde.

- As técnicas de planejamento do setor saúde.

- Institucionalização do processo de planejamento do setor saúde em nível estadual.

São êstes os comentários e informaçóes que nos ocorre oferecer aos colegas, a propósito do preparo de pessoal em planejamento do setor saúde, em alguns países das Américas. Restam por fazer, à guisa de conclusões, três rápidas consideraçôes:

1) Desde o seu início, os cursos de planejamento vêm passando por uma evo. lução contínua, sofrendo as alterações que a experiência indica, de sorte a terem seu conteúdo cada vez mais ajustado à realidade dos nossos países. Tal como o próprio planejamento, os cursos de pla. nejamento constituem um processo circular acumulativo, no sentido de que a avaliação realizada ao final de cada um dêles conduz ao aperfeiçoamento do curso seguinte.

2) Condicionando e favorecendo um processo de mudança, os cursos de planejamento do setor saúde refletem uma atitude de intranquilidade e inconformismo dos profissionais de saúde, e representam a contribuição específica de seu campo para o planejamento do desenvolvimento econômico e social dos nossos países. Considerados sob essa perspectiva, estamos plenamente convencidos de que tais cursos terão que ter caráter irreversivel.

3) E retornamos agora ao ponto de partida, quando aludimos ao papel de destaque que a Organização Mundial da Saúde tem desempenhado na formação de pessoal para os serviços de saúde. Os senhores sentiram a presença da Organização Mundial da Saúde — através de seu organismo regional para as Américas em todos os cursos de planejamento do setor saúde até agora realizados entre nós. Sem a colaboração decisiva da Organização Panamericana da Saúde, a implantação e consolidação dêsses cursos teria sido - não podemos dizer impossível mas, seguramente, muito mais difícil.

\section{S U M M A R Y}

After focusing the importance of human resources for carrying out health programs which have deserved the attention of WHO, the Author emphasizes that special consideration has also been given lately to the preparation of the planning staff.

An evaluation of the objectives and contents of courses on health planning is presented, followed by a comparison of courses which tock place in the USA, Trinidad and Tobago, Chile and Brazil.

The Author concludes emphasizes the role of WHO - through its Regional Office - in the implementation and consolidation of such courses in the Americas. 
RAmOS, R. - O treinamento de planejadores do setor saúde. Rev. Saúde públ., S. Paulo, 2(2) :207-215, dez. 1968.

\section{B I B L I O G R A F I A}

TEJADA de RIVERO, D. A. - Los servicios administrativos en los planes nacionales de salud. In: SEMINARIO sobre Orga- nización y Administración de los Servicios de Salud Publica para los Paises de America del Sur, 2o, Buenos Aires, 1965. Informe... Washington, D. C., OPAS, 1965. p. 33 